\title{
THE BIOLOGY OF THE SPIDER WASP, PEPSIS THISBE (HYMENOPTERA: POMPILIDAE) FROM TRANS PECOS, TEXAS. II. TEMPORAL PATTERNS OF ACTIVITY AND HUNTING BEHAVIOR WITH SPECIAL REFERENCE TO THE EFFECTS OF EXPERIENCE
}

\author{
By Fred Punzo \\ Dept. of Biology \\ Box 5F \\ University of Tampa \\ Tampa, FL 33606
}

\begin{abstract}
The temporal pattern of activity and hunting behavior of the spider wasp, Pepsis thisbe, from Trans Pecos, Texas are described. Females exhibited a bimodal pattern with peak periods of hunting activities occurring between 0800-0959 and 1600-1759 hr. The lowest levels of activity (1100-1359 hr) occurred when ambient temperatures exceeded $38^{\circ} \mathrm{C}$. Activity declined abruptly after 1800 $\mathrm{hr}$ indicating a strong preference for diurnal activity in this species. The behavioral components of the hunting sequence consist of an initial approach and antennation of the host, grooming, antennation and paralyzation followed in some cases by lapping, oviposition, burial of the host, and closure of the nest. The time required to complete the hunting sequence was recorded for both field and laboratory encounters between a wasp and spider. The amount of time required by a female wasp to complete the initial approach and antennation-paralyzation sequences decreased significantly as a function of increasing encounter experience. The spider is stung most frequently $(>80 \%)$ through the intersegmental membrane between the sternum and coxa of the first leg. Whether or not a wasp exhibits lapping behavior is determined by the amount of time spent in flight searching for a host burrow.
\end{abstract}

Manuscript received 22 August 1994. 


\section{INTRODUCTION}

The hunting behavior of female tarantula hawk wasps of the genus Pepsis (Hymenoptera: Pompilidae) has captured the imagination of scientists and amateur naturalists since the early descriptions of Buckley (1862), Petrunkevitch $(1926,1952)$, and Passmore (1936). Wasps of this genus, as well as Hemipepsis, are common representatives of the desert arthropod fauna of the southwestern United States (Hurd, 1952; Punzo, 1995).

The hunting behavior of Pepsis and Hemipepsis wasps has been traditionally viewed as an excellent example of instinctive behavior (Petrunkevitch, 1926; Williams, 1956; Cazier and Mortenson, 1964) comprised of genetically pre-programmed, rigid behavioral acts. However, recent studies on Pepsis formosa (Punzo and Garman, 1989; Punzo, 1991) have shown that there is some behavioral plasticity exhibited by the female wasp during an encounter with its host. Its hunting behavior can be analyzed in terms of discrete behavioral acts (Punzo, 1991): 1) initial approach and antennation of the spider (AP); 2) moving away and grooming (MG);3) antennation and paralyzation (AnP); burial and oviposition (BO); and closure of the nest $(\mathrm{C})$. The amount of time required by the wasp to complete the entire hunting sequence decreased significantly with increasing number of encounters; however, only the AP and AnP components improved with experience (Punzo and Garman, 1989).

The purpose of the present study was to describe the hunting behavior and temporal pattern of activity for Pepsis thisbe Lucas from the Trans Pecos Region of Texas. Little information is available for this species. In this region, Pepsis thisbe females selectively hunt the theraphosid spider, Aphonopelma echina Chamberlin (Orthognatha: Theraphosidae). This spider is primarily sedentary and occupies burrows constructed in sandy or adobe soils (Punzo, 1988, 1989).

\section{Materials AND Methods}

Studies were conducted on wasps located within a $7-\mathrm{km}$ radius of Study Butte (Brewster Co., Texas; $32^{\circ} 24^{\prime} \mathrm{N}, 103^{\circ} 12^{\prime} \mathrm{W}$; elevation: $920 \mathrm{~m}$ ), located within the northern region of the Chihauhuan Desert. A detailed description of the study area is given by Punzo (1995). 
Adult wasps were collected using light traps and sweep nets and maintained individually in clear plastic Drosophila vials where they were fed a mixture of honey and water. Host spiders were trapped at night at the entrances to their burrows as described by Punzo (1989). Some spiders were transported back to my laboratory and housed separately in plastic cages. They were maintained on a diet of grasshoppers and crickets.

I collected eggs and pupae of $P$. thisbe from the burrows of parasitized spiders as described previously by Punzo and Garman (1989). Emergent adult males and females were placed together in 100-gal aquaria and allowed to mate in order to obtain gravid females. All female wasps used in encounter experiments under field and laboratory conditions had no prior experience with host spiders and were described as naive. Statistical methods used throughout this study follow those described by Sokal and Rohlf (1981).

I determined the temporal pattern of activity for hunting in this study area. Whenever a female wasp was observed actively searching on the ground, it was collected with a sweep net and the time of day (CST) was recorded. Similar data were recorded for wasps observed in an actual encounter with a host spider. Data were collected for a total of 315 wasps and the results expressed as the percentage of wasps engaged in hunting behavior at various times of the day ( $2 \mathrm{hr}$ intervals; i.e., 0400-0559, etc.).

To describe the hunting behavior of this species, encounters between naive female wasps and their hosts were recorded on film, both in the field and laboratory, using a Nikon FE2 35mm camera and a Panasonic L3 video recorder. I used female wasps (body length: $31.3-35.1 \mathrm{~mm}$ that had no previous encounter with a spider reared from larvae. For field studies, a previously located spider burrow was covered with a spherical, dome-shaped cone $60 \mathrm{~cm}$ in diameter and $30 \mathrm{~cm}$ in height, constructed of fine-mesh aluminum window screening and provided with an opening on top into which a Drosophila vial housing a wasp could be inserted. The dome was positioned so that the entrance to the burrow was located in the center of the dome. The presence of silk covering the burrow entrance is a reliable indication that the burrow is occupied by a spider (Punzo, 1989). To initiate an encounter, a vial containing one female wasp was placed in the opening at the top of the dome 
and the wasp was allowed to enter. A Timex stopwatch (L210) was used to determine the amount of time required for the wasp to perform various behavioral acts of the hunting sequence. Ongoing studies had indicated that most wasps in this area exhibit hunting behavior between 0800-0959 and 1600-1759 CST and so encounters were staged during these time intervals. Each wasp was subjected to encounters with 10 hosts to determine if there was any improvement in performance as a function of increasing encounter experience. Analysis of data was restricted to only those encounters between wasps $(\mathrm{N}=27)$ and hosts within a certain size range $(7.4-8.1 \mathrm{~g})$ in order to minimize any confounding effect of host size on hunting behavior.

The chamber and procedure used to analyze encounters in the laboratory have been previously described by Punzo and Garman (1989). All observations were conducted through a one-way mirror to minimize extraneous disturbances. A burrow was constructed at one end of the chamber which ran along one of its transparent sides so that events within the burrow could be observed. A female spider (mean weight: $7.4 \pm 0.6 \mathrm{~g}$ ) was placed within the burrow 24 $\mathrm{hr}$ prior to an encounter sequence. Each encounter was initiated by introducing a naive female wasp into the chamber and the time required to complete various behavioral components of hunting was recorded with a stopwatch. Each wasp was subjected to encounters with 10 hosts. Data were collected for 65 wasps (body length: $31.8-33.5 \mathrm{~mm}$ ).

For field and laboratory encounters, hunting behavior was analyzed in terms of the following components: initial approach and antennation of the host (AP); moving away and grooming (use of mouthparts to clean antennae, (MG); antennation and paralyzation (AnP); burial and oviposition (BO); and closure of the burrow (C). Analysis of films and photographs also allowed me to collect data on preferred sites for insertion of stinger and the percentage of wasps exhibiting what I will refer to as lapping behavior (drinking of host body fluids emanating from the wound site where the sting had been inserted, or from the buccal cavity of the host).

I also conducted experiments to determine whether or not the degree of physical activity of the wasp prior to an encounter had any effect on the frequency of lapping behavior. Preliminary observations had indicated that wasps exhibit lapping in fewer than $40 \%$ 
of their encounters with a host. Perhaps this behavior is conducted to replenish nutrients and water lost during unusually lengthy foraging flights which may encompass distances of over $3 \mathrm{~km}$ (personal observation). If so, then the frequency of lapping should increase as a function of increased flight time. To test this, I forced female wasps to perform fixed flight bouts of 0 (controls), 1, 2, 3, 4 or $5 \min (\mathrm{N}=20$ wasps at each time interval). Prior to testing, each wasp was anesthetized with carbon dioxide. A drop of warm paraffin wax was affixed to the dorsal surface of the prothorax and allowed to harden. An insect pin (size 1) was inserted into the ball of wax. The wasp was then suspended by the pin from a horizontal metal rod attached to ring stand and allowed to recover until it was alert (moving its head, legs and antennae). The legs of the wasp were directed downward onto a spherical piece of styrofoam $(2 \mathrm{~cm}$ in diameter). The suspended wasp was positioned facing an air hose at a distance of $10 \mathrm{~cm}$, so that a gentle stream of compressed air could be directed at the wasp. When the styrofoam sphere was gently pulled away from the legs with forceps, the wasp would begin to exhibit flight behavior. After the allotted time, the air was turned off and the sphere positioned beneath the wasp which grasped it and then ceased flight behavior. The wax and pin were removed using a dilute acetone solution and forceps. The wasp was then placed into the encounter chamber as described previously and allowed to interact with its host. Its hunting behavior was observed and the following data recorded: (1) the presence or absence of an attack response; (2) if an attack occurred, did the wasp exhibit lapping behavior?

\section{RESULTS}

The behavioral acts which comprise the hunting behavior of $P$. thisbe are listed in Table 1. No meaningful differences were observed between encounters in the field versus those staged in the laboratory. In the field, female wasps were observed to leave perch sites and exhibit what appear to be random flight search patterns which lasted 1-2 min. The wasp then alights on the ground and begins to walk rapidly over the surface while tapping the substrate in rapid fashion with the antennae. In some cases, a wandering male spider is encountered as it moves along the ground. This occurs most frequently during those months (July-August) in 
which A. echina males seek out females for mating. More frequently, a burrow occupied by a spider is located. In these cases, the wasp uses its mandibles to cut through the silk covering at the burrow entrance. It has been suggested that the wasp relies primarily on alfactory cues to ascertain the suitability of the host (Petrunkevitch, 1952; Punzo, 1990, 1991). The wasp then enters the burrow and forces the spider to the surface. Apparently the physical dimensions of the burrow are too confining for the wasp to attack the spider in its retreat. Once at the surface, the wasp begins to explore the surface of the spider with its antennae (antennation). The host may exhibit a threat display in which it raises its front legs and exposes the fangs. However, the spider makes no attempt to strike at the wasp. The wasp continues antennation for a variable period of time and then moves a short distance away $(9-15 \mathrm{~cm})$ to groom. During grooming, both antennae are alternately passed through the mandibles for cleaning purposes. During this time, the spider makes no attempt to escape. The wasp returns to its host and resumes antennation. After a variable period of time, it suddenly darts under the spider and seizes one of the rear legs with its mandibles while bracing its own metathoracic legs against the pedipalps of the host making a strike by the spider more difficult. The spider is usually flipped over on its back at this time. The sting is inserted and the host is paralyzed very rapidly $(1.5-2.5 \mathrm{sec})$. The effect of the wasp venom can be readily seen as the legs of the spider begin to curl inward and all movement ceases.

The sites at which the sting is inserted can vary, although the most frequent site $(81-86 \%)$ is the intersegmental membrane between the sternum and coxa of the first leg (contingency test, $\left.\mathrm{X}^{2}=34.6, \mathrm{p}<0.001\right)$. This is the region in which the large subesophageal ganglion which supplies innervation to the muscles of the legs, pedipalps and chelicerae is located (Foelix, 1979). Unlike many other solitary wasps whose venom has only transitory effects (Ross et al., 1988), the venom of Pepsis wasps paralyzes the host permanently. The venoms of many solitary wasps have been shown to exhibit strong neuromuscular effects (Piek, 1981). For $A$. echina, the paralysis is permanent. The spider shows no visible signs of recovery and remains paralyzed until it is finally killed by the developing wasp larva. In no case did $P$. thisbe sting its host 
Table 1. Sequence of behavioral acts comprising the hunting behavior of the spider wasp, Pepsis thisbe, and associated behaviors of its host, Aphonopelma echina.

\begin{tabular}{|c|c|c|}
\hline & Female wasp behavior & Host spider behavior \\
\hline 1. & $\begin{array}{l}\text { Search for occupied spider } \\
\text { burrow }\end{array}$ & \\
\hline 2. & $\begin{array}{l}\text { Enters burrow and forces } \\
\text { spider to the surface }\end{array}$ & \\
\hline 4 & Antennation of the bost & 3. Emerges from burrow \\
\hline 4. & Airetimation or tie nost & $\begin{array}{l}\text { 5. Assumes defensive } \\
\text { posture }\end{array}$ \\
\hline 6. & $\begin{array}{l}\text { Continues exploration of } \\
\text { body surface of the host } \\
\text { spider (antennation) }\end{array}$ & \\
\hline 7. & $\begin{array}{l}\text { Cleaning of the antennae } \\
\text { (grooming) }\end{array}$ & \\
\hline 8. & $\begin{array}{l}\text { Resumes antennation of } \\
\text { spider }\end{array}$ & \\
\hline 9. & Seizes leg of spider & \\
\hline 11. & $\begin{array}{l}\text { Presses tarsi against legs } \\
\text { of spider }\end{array}$ & 10. Attempts to escape \\
\hline 12. & Insertion of sting & \\
\hline 14. & Resumes grooming & 13. Paralysis \\
\hline 15. & $\begin{array}{l}\text { Excavation of burrow (if } \\
\text { spider burrow is not } \\
\text { available) }\end{array}$ & \\
\hline 16. & $\begin{array}{l}\text { Drags spider backwards } \\
\text { into burrow }\end{array}$ & \\
\hline 17. & $\begin{array}{l}\text { Oviposition of a single } \\
\text { egg on the abdomen of } \\
\text { the spider }\end{array}$ & \\
\hline 18. & Closure of burrow entrance & \\
\hline
\end{tabular}

more than once. With a host potentially capable of delivery a toxic and fatal bite of its own, the adaptive significance of a fast-acting venom is obvious. Wasps showed no preference for the right vs. the left side of the host body, and the frequency of sting insertion sites was the same for male and female hosts.

Less frequently $(12-16 \%)$, the sting was inserted into the membrane between the sternum and coxa of leg 2 or the labium and 
sternum (2-3\%). Individual wasps showed some variation in behavior regardless of whether or not it had previously attacked a host.

Following paralyzation, the wasp may drink (lapping) from the host body fluids oozing from the wound site at which the sting was inserted or lap at moisture located around the buccal cavity. The frequency of occurrence for lapping was $34.7 \%$ at the wound site, and $3.6 \%$ at the mouth.

The wasp then moves away from the paralyzed host and again grooms its antennae (Table 1). If a male spider had been attacked while wandering over the surface of the ground, the wasp will excavate a shallow, curvilinear burrow (length: 16-25 cm; diameter: $22-28 \mathrm{~mm}$ ). Most frequently, the burrow of the spider (male or female) is used as a nest. The wasp grasps one of the hind legs of the host and drags the spider backwards into the burrow. As stated earlier, laboratory staged encounters allowed me to observe events inside the burrow. A single egg is attached at one end to the ventral surface of the abdomen just above the posterior opening to the book lungs. The free end of the egg extends laterally along the abdomen. Once the egg is laid, the wasp leaves the burrow and seals the entrance. Soil near the entrance is loosened with the mandibles or prothoracic legs and compacted with the abdomen.

The amount of time required to complete all components of the hunting sequence and the effects of encounter experience on overall performance are shown in Table 2 . The results indicate that the hunting behavior of naive $P$. thisbe females improves with experience. In field observations, the time required for the entire hunting sequence decreased from a mean of $208.1 \mathrm{~min}$ for the first encounter with a host to $150.1 \mathrm{~min}$ after 10 encounters $(t=8.67$, $\mathrm{df}=49, \mathrm{p}<0.01)$. In laboratory experiments, the time required decreased from 165.3 to $117.2 \min (t=7.32$, $\mathrm{df}=49, \mathrm{p}<0.01)$. The results also indicate that only certain behavioral components of the hunting sequence improve with experience (AP and AnP) whereas others do not (MG, BO, and C). Thus, AP and AnP exhibit a degree of behavioral plasticity characteristic of more open behavioral programs influenced by learning whereas $\mathrm{MG}, \mathrm{BO}$, and $\mathrm{C}$ can be characterized as rigid, closed behavioral programs. Similar results were reported for $P$. formosa (Punzo and Garman, 1989) which occurs sympatrically with $P$. thisbe and can utilize the same 
Table 2. Effect of encounter experience on the time ( $\mathrm{min}$ ) required for naive Pepsis thisbe females to complete the various behavioral components of the hunting sequence. Values represent means $( \pm$ S.D.) for wasps under both field $(N=27)$ and laboratory $(\mathrm{N}=65)$ conditions $^{1}$.

\begin{tabular}{|c|c|c|c|c|c|c|}
\hline \multirow[b]{2}{*}{ Encounter } & \multicolumn{5}{|c|}{ Behavioral components } & \multirow[b]{2}{*}{ Total } \\
\hline & AP & MG & AnP & $\mathrm{BO}$ & $\overline{\mathrm{C}}$ & \\
\hline \multicolumn{7}{|l|}{ Field } \\
\hline 1 & $28.3(7.1)$ & $12.5(2.5)$ & $19.8(4.3)$ & $49.6(6.8)$ & $97.9(8.5)$ & $208.1(10.2)$ \\
\hline 2 & $31.1(5.5)$ & $13.4(3.7)$ & $22.7(2.7)$ & $54.7(8.3)$ & $95.3(9.1)$ & $217.2(13.6)$ \\
\hline 3 & $21.5(2.7)$ & $10.1(2.1)$ & $17.7(4.4)$ & $49.9(6.7)$ & $85.9(7.7)$ & $185.1(8.8)$ \\
\hline 4 & $18.6(2$ & $12.5(3.5)$ & 13.6( & $57.2(7.1)$ & $91.8(6.8)$ & $193.7(11.6)$ \\
\hline 5 & ) & 10.9 & 1) & 47.8 & 9) & $160.4(8.4)$ \\
\hline 6 & 3) & 12.6 & 9) & 43.2 & 79.60 & 148.5 \\
\hline 7 & 5) & 10.2( & 6.8 & 50.1 & 2) & $156.1(10.5)$ \\
\hline 8 & 4) & 11.7 & 5.3 & 48.1 & 79.3 & $150.6(7.9)$ \\
\hline 9 & $5.7(0.6)$ & $13.1(2.2)$ & 4.7( & $43.6(6.1)$ & $82.7(5.9)$ & $149.8(10.1)$ \\
\hline 10 & $6.4(0.4)$ & $11.9(1.7)$ & $5.5(0.3)$ & $46.1(7.2)$ & 80.2 & 150.1 \\
\hline \multicolumn{7}{|l|}{ Laboratory } \\
\hline 1 & $25.9(3.9)$ & $15.8(5.2)$ & 17.3 & 41.7 & 4.6 & 165 \\
\hline 2 & $21.4(5.1)$ & $21.1(7.2)$ & 15.7 & 60.3 & 79.8 & $198.3(15.8)$ \\
\hline 3 & $25.2(4.8)$ & $14.8(5.6)$ & $18.4(5.1)$ & $43.8(6.2)$ & $57.6(7.3)$ & $159.8(12.1)$ \\
\hline 4 & $20.4(3.7)$ & $11.9(4.2)$ & 12.9 & $59.9(7.7)$ & 79.4 & $184.5(14.3)$ \\
\hline 5 & $11.3(4.1)$ & 12.5 & 10.1 & $51.3(6.1)$ & 63.3 & 2.9) \\
\hline 6 & 8.3( & 13.9 & t) & 40.9 & 72.3 & 10.1) \\
\hline 7 & 2( & 15.1 & 4.7 & 34.4 & 74.1 & 13.6) \\
\hline 8 & ) & 16 & 3. & 40.1 & 52 & 117.5 (11.5) \\
\hline 9 & ) & & & 39.1 & $60.3(7.7)$ & 121.1 \\
\hline 10 & $5.7(0.3)$ & $13.1(4.5)$ & $5.1(0.4)$ & $41.2(6.7)$ & $52.1(6.3)$ & $117.2(10.2)$ \\
\hline \multicolumn{7}{|c|}{$\begin{array}{l}{ }^{1} \text { ANOVA showed the overall effect of encounter experience on the total time } \\
\text { required to complete hunting behavior to be significant under both field }(\mathrm{F}=82.8 \text {; } \\
\text { df }=9,133 ; \mathrm{p}<0.001) \text { and laboratory }(\mathrm{F}=74.2 ; \mathrm{df}=9,227 ; \mathrm{p}<0.001) \text { condi- } \\
\text { tions. A Duncan multiple range test (Sokal and Rohlf, 1981) showed no signifi- } \\
\text { cant improvement in performance after encounter } 7 \text {. Encounter experience had no } \\
\text { significant effect on MG, BO, and C components of behavior. }\end{array}$} \\
\hline
\end{tabular}

host. However, $P$. formosa females required a longer period of time (237 $\mathrm{min}$ ) to complete the hunting sequence in initial encounters.

The amount of time spent in flight before an encounter has a significant effect $\left(X^{2}=35.7, p<0.01\right)$ on the probability of an attack. Upon the first presentation of a host, newly inseminated control wasps (no forced flight) attack at a frequency of $74 \%$. A 
forced flight time of one min has no significant effect $(p>0.5)$ on the attack rate (68\%). However, after 2 and $3 \mathrm{~min}$ of forced flight, the frequency of attack decreases to $29 \%$ and $5 \%$, respectively $(\mathrm{p}<$ 0.01 ). Wasps forced to fly 4-5 min do not exhibit any attack behavior until given a rest period of at least $60 \mathrm{~min}$ (personal observation).

Flight time was also found to affect the frequency of lapping behavior. Naive control wasps exhibit lapping very infrequently (3-7\%). This increases to $10 \%$ (mouth site) and $56 \%$ (wound site), and $20 \%$ and $73 \%$, after 2 and 3 min of flying, respectively. When lapping behavior is exhibited, the wound site is preferred to a much greater extent than the mouth of the host.

The temporal pattern for hunting behavior by female wasps is shown in Fig. 1. Females exhibit a bimodal activity pattern with the highest percentages of wasps searching for burrows between $0800-0959(25.3 \%, \mathrm{~N}=315)$ and $1600-1759 \mathrm{hr}(33.3 \%)$. Application of $\log$ frequency analysis (Sibly et al., 1990) indicated that searching behavior increases significantly during these time periods $(\mathrm{F}=15.7, \mathrm{p}<0.01)$. From $1400-1559 \mathrm{hr}, 13.9 \%$ of the total number of wasps observed were active. Over $39 \%$ of the wasps exhibited searching behavior between 1400 and $1759 \mathrm{hr}$. Lowest peaks of activity occurred between $2200-1559 \mathrm{hr}$ or at times when ambient temperatures exceeded $38^{\circ} \mathrm{C}$ (1100-1359). Activity declined abruptly after $1800 \mathrm{hr}$ (from $33.3 \%$ at $1600-1759 \mathrm{hr}$ to $7.9 \%$ at $1800-1959 \mathrm{hr}$ ). This indicates a strong preference for diurnal activity in this species.

\section{Discussion}

It is becoming increasingly evident that many behavioral acts previously considered to be instinctive can exhibit varying degrees of plasticity (Punzo, 1985, 1991). This is certainly the case for the hunting behavior of Pepsis wasps. In P. thisbe, specific behavioral components of the hunting sequence improved with practice whereas others did not. This improvement in performance as a function of encounter experience suggests that learning may contribute to the overall fitness of these spider wasps. In terms of energy budgets and optimal foraging theory (Krebs, 1978; O'Brien et al., 1990), time spent in locating and handling a required resource is rendered unavailable for other important activities such 


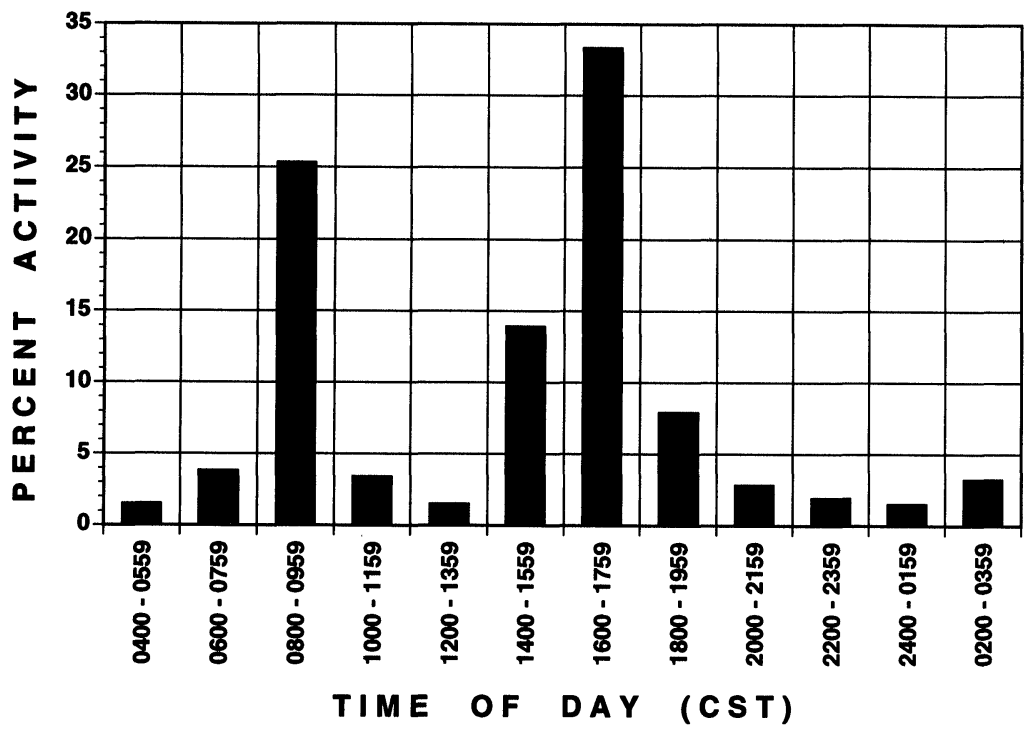

Fig. 1. Temporal patterns of activity for hunting in the spider wasp, Pepsis thisbe $(\mathrm{N}=315$ females). Data represent percent activity at various intervals over a $24-\mathrm{hr}$ period. CST $=$ Central Standard Time.

as feeding and mating. By decreasing the amount of time required to subdue its prey, $P$. thisbe can minimize its foraging costs and increase fitness. Selection should favor the evolution of adaptive behavioral programs that allow for a certain degree of plasticity (Punzo, 1985). It is also interesting to note that those specific behavioral components that improve with experience (AP and AnP) are precisely those that are most closely related with potentially unpredictable behavioral acts of the host. During AP and AnP, the wasp is in close proximity to its formidable host which is still alert and active. However, no unpredictable interactions are associated with the MG (wasp is out of striking range of the host) or BO and C (host is immobilized) components of hunting. Since olfactory cues leading to paralyzation apparently play an important role in Pepsis hunting strategies (Petrunkevitch, 1952; Punzo, 1991), the grooming of the antennae (MG) is very important. The wasp is deliberate and meticulous in its cleaning movements which 
are under the influence of certain biomechanical constraints. A certain minimum amount of time is required to complete the mechanical movements associated with dragging the host into the burrow, oviposition, and closure of the burrow entrance. Under these biomechanical constraints, the capacity for plasticity would not be particularly adaptive.

The results also indicate a strong site preference for insertion of the sting by $P$. thisbe. Stinging patterns in other species of wasps are species-specific and can also vary considerably between species (see review by Steiner, 1986). However, the sting is usually inserted at a site very close to a major nerve center affecting the locomotor activities of the host. In many insect hosts, the membrane between the head and thorax near the thoracic ganglia is chosen. In other cases, the wasp may sting the host in several locations. In spiders, a site close to the subesophageal ganglion is usually selected. This was the case in the present study.

It was also demonstrated for the first time that lapping behavior is influenced by the degree of physical activity by the wasp prior to an encounter with a host. Although this behavior had been described by early investigators (Petrunkevitch, 1926; Passmore, 1936), the reason(s) why it occurs in some encounters and not in others has never been satisfactorily explained. The energetic demands of insect flight are well known. Also, the xeric conditions which frequently confront diurnal desert arthropods can lead to significant evaporative water loss and osmotic stress (CloudsleyThompson, 1975). Presumably, lapping allows the wasp to replenish nutrients and water required to meet the energetic demands of flight. The frequency of this behavior should be related to the amount of energy used. The results of this study support this view. The mouth of the host represents a potential source of water whereas hemolymph oozing from the wound site can provide both water and nutrients. It is not surprising that $P$. thisbe showed a preference for the wound site.

\section{ACKNOWLEDGEMENTS}

I thank T. Punzo, J. Bottrell, and T. Ferraioli for assistance in collecting and observing wasps in the field, Dr. B. Garman (Dept. of Mathematics) for assistance in statistical analyses, and anonymous reviewers for helpful comments on an earlier draft of the 
manuscript. I also thank the University of Tampa for Faculty Development Grants from 1986-1993 and for a sabatical leave in 1986 which made much of this work possible.

\section{Literature Cited}

Buckley, S. B. 1862. The tarantula (Mygale hentzii Girard) and its destroyer (Pompilus formosus Say). Proc. Ent. Soc. Philadelphia 1:138-139.

Cazier, M. A. and M. Mortenson. 1964. Bionomical observations on tarantula hawks and their prey (Hymenoptera : Pompilidae): Pepsis. Ann. Ent. Soc. Amer. 57:533-541.

Cloudsley-Thompson, J. L. 1975. Adaptations of arthropods to arid environments. Ann. Rev. Ent. 20:261-263.

Evans, H. E. 1953. Comparative ethology and the systematics of spider wasps. Syst. Zool. 2:155-172.

Foelix, R. F. 1979. Biology Of Spiders. Harvard University Press, Cambridge, Massachusetts. 306 pp.

Hurd, P. D. 1952. Revision of the Nearctic species of the pompilid genus Pepsis (Hymenoptera : Pompilidae). Bull. Amer. Mus. Nat. Hist. 98:261-334.

Krebs, J. R. 1978. Optimal foraging: decision rules for predators. In: Behavioral Ecology: An Evolutionary Approach (Edited by J. R. Krebs and N. B. Davies). Blackwell Publs., Oxford. pp. 23-63.

O'Brien, W. J. H., Browman, H. I. and B. Evans. 1990. Search strategies of foraging animals. Amer. Scient. 78:152-160.

Passmore, L. 1936. Tarantula and tarantula hawk. Nat. Mag. 27:155-159.

Petrunkevitch, A. 1926. Tarantula versus tarantula hawk: a study in instinct. J. Exp. Zool. 45:367-394.

Petrunkevitch, A. 1952. The spider and the wasp. Sci. Amer. 187:20-33.

Piek, T. 1981. Solitary wasp venoms as tools for the study of neuromuscular transmission. Comp. Biochem. Physiol. 68C:75-84.

Punzo, F. 1985. Recent advances in behavioral plasticity in insects and decapod crustaceans. Fla. Entomol. (Insect Behavioral Ecology Symposium) 68:89-104.

Punzo, F. 1988. Learning and localization of brain function in the tarantula spider, Aphonopelma chalcodes (Orthognatha : Theraphosidae). Comp. Biochem. Physiol. 89A:465-470.

Punzo, F. 1989. Effects of hunger on prey capture and ingestion in Dugesiella echina Chamberlin (Orthognatha : Theraphosidae). Bull. Br. Archnol. Soc. 8:72-79.

Punzo, F. 1990. The hemolymph composition and neurochemistry of the spider wasp, Pepsis formosa (Hymenoptera: Pompilidae). Comp. Biochem. Physiol. 96A:341-345.

Punzo, F. 1991. Neurochemical events associated with learning and hunting behavior in the spider wasp, Pepsis formosa (Say) (Hymenoptera : Pompilidae). Fla. Scient. 54:51-61.

Punzo, F. 1995. The biology of the spider wasp, Pepsis thisbe (Hymenoptera : Pompilidae) from Trans Pecos, Texas. I. Adult morphometrics, larval development and the ontogeny of larval feeding patterns. Psyche (in press). 
Punzo, F. and B. Garman. 1989. Effects of encounter experience on the hunting behavior of the spider wasp, Pepsis formosa (Say) (Hymenoptera: Pompilidae). Southwest. Nat. 34:513-518.

Ross, D. C., Herzog, G. A., Brady, U. E. and J. W. Crim. 1988. Differential effects of Vespula wasp venom and its components, mastoparan and bradykinin; toxicity and feeding tests with the cottom bollworm. Comp. Biochem. Physiol. 89C:299-303.

Sibly, R. H., Nott, H. M. and D. Fletcher. 1990. Splitting behavior into bouts. Anim. Behav. 39:63-69.

Sokal, R. R. and F. J. Rohlf. 1981. Biometry. 2nd ed., W. H. Freeman and Company, New York, $859 \mathrm{pp}$.

Steiner, A. L. 1986. Stinging behavior of solitary wasps. In: Venoms of The Hymenoptera (Edited by T. Piek), Academic Press, New York. pp. 63-160.

Williams, F. X. 1956. Life history studies of Pepsis and Hemipepsis wasps in California (Hymenoptera: Pompilidae). Ann. Ent. Soc. Amer. 49:447-466. 

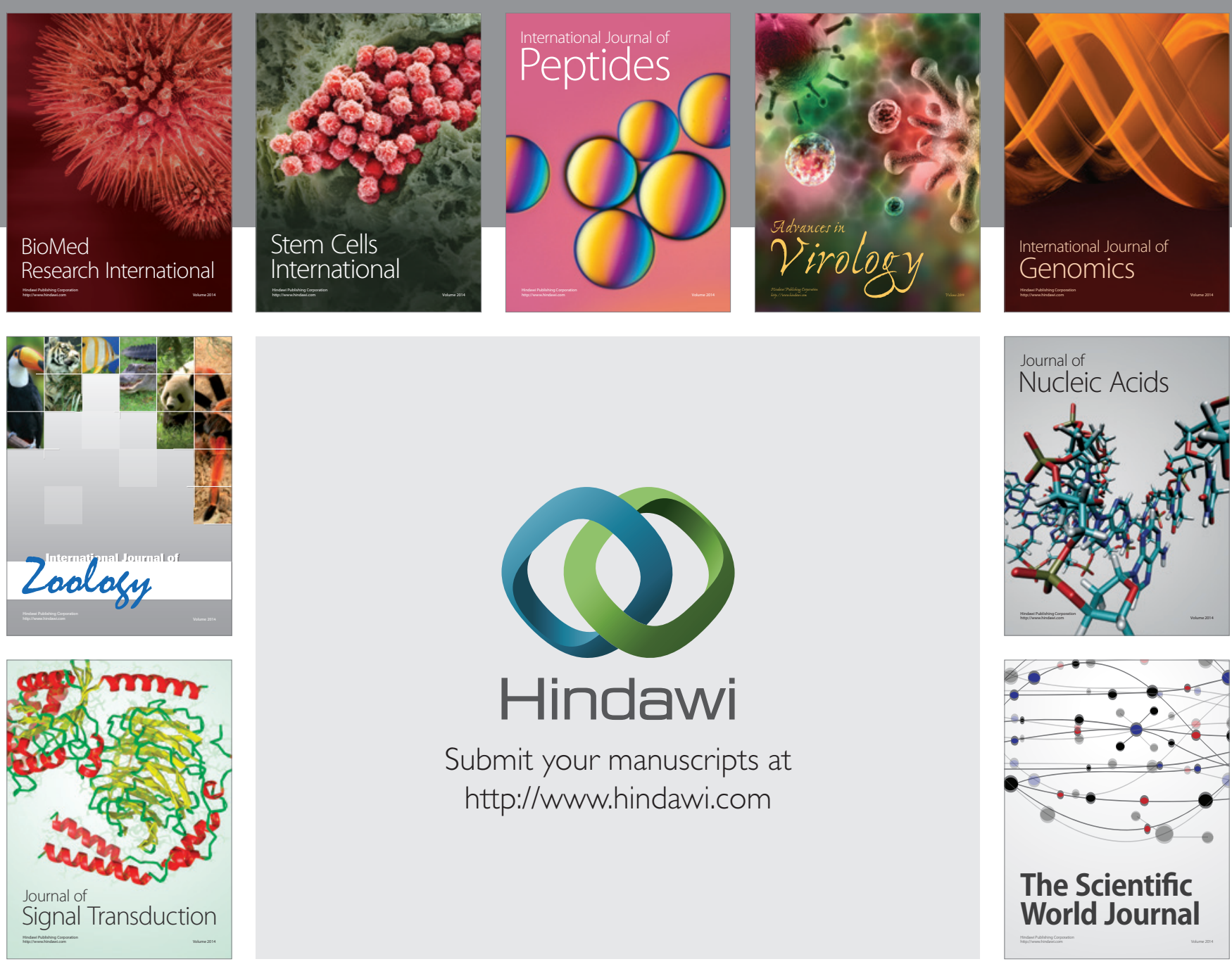

Submit your manuscripts at

http://www.hindawi.com
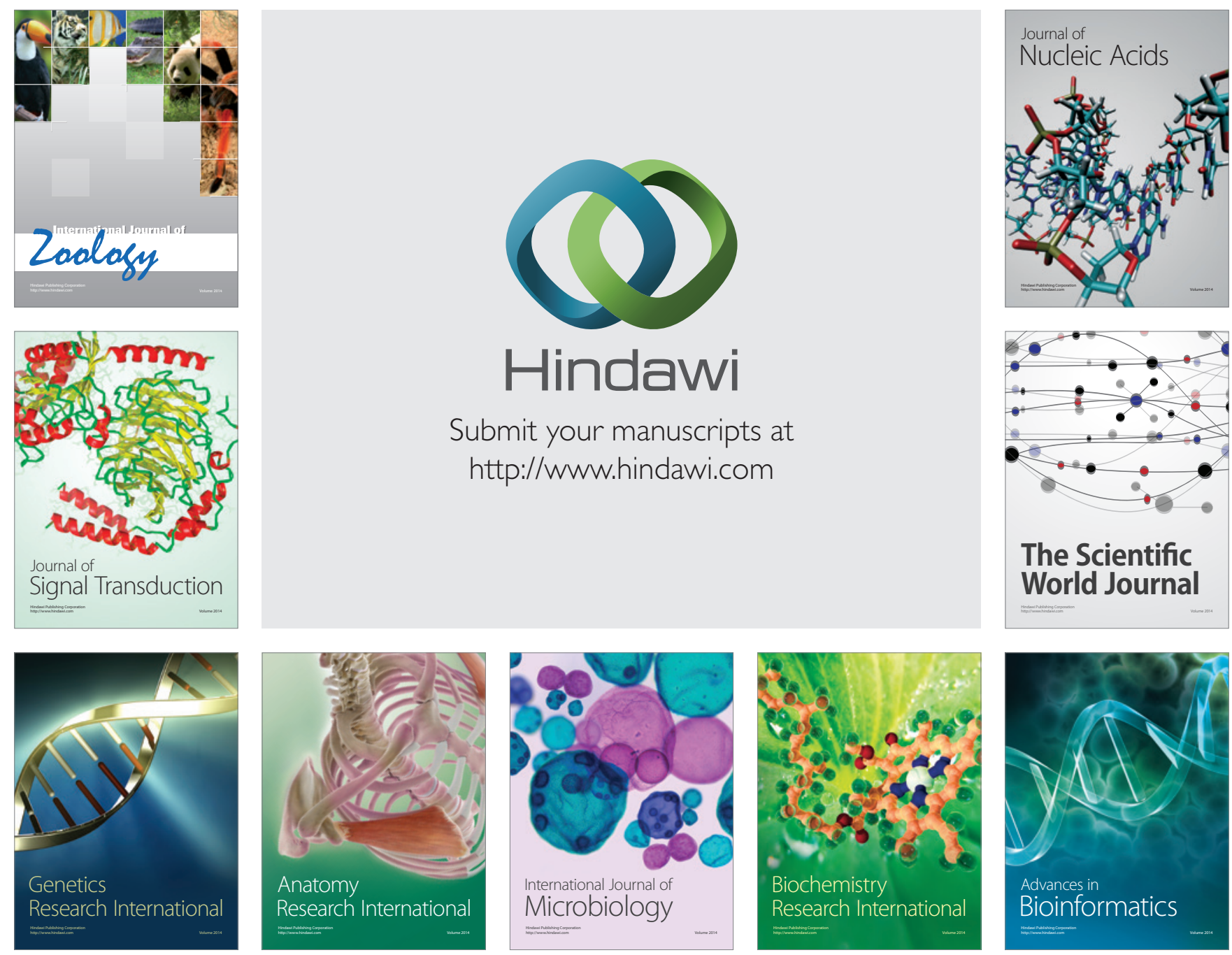

The Scientific World Journal
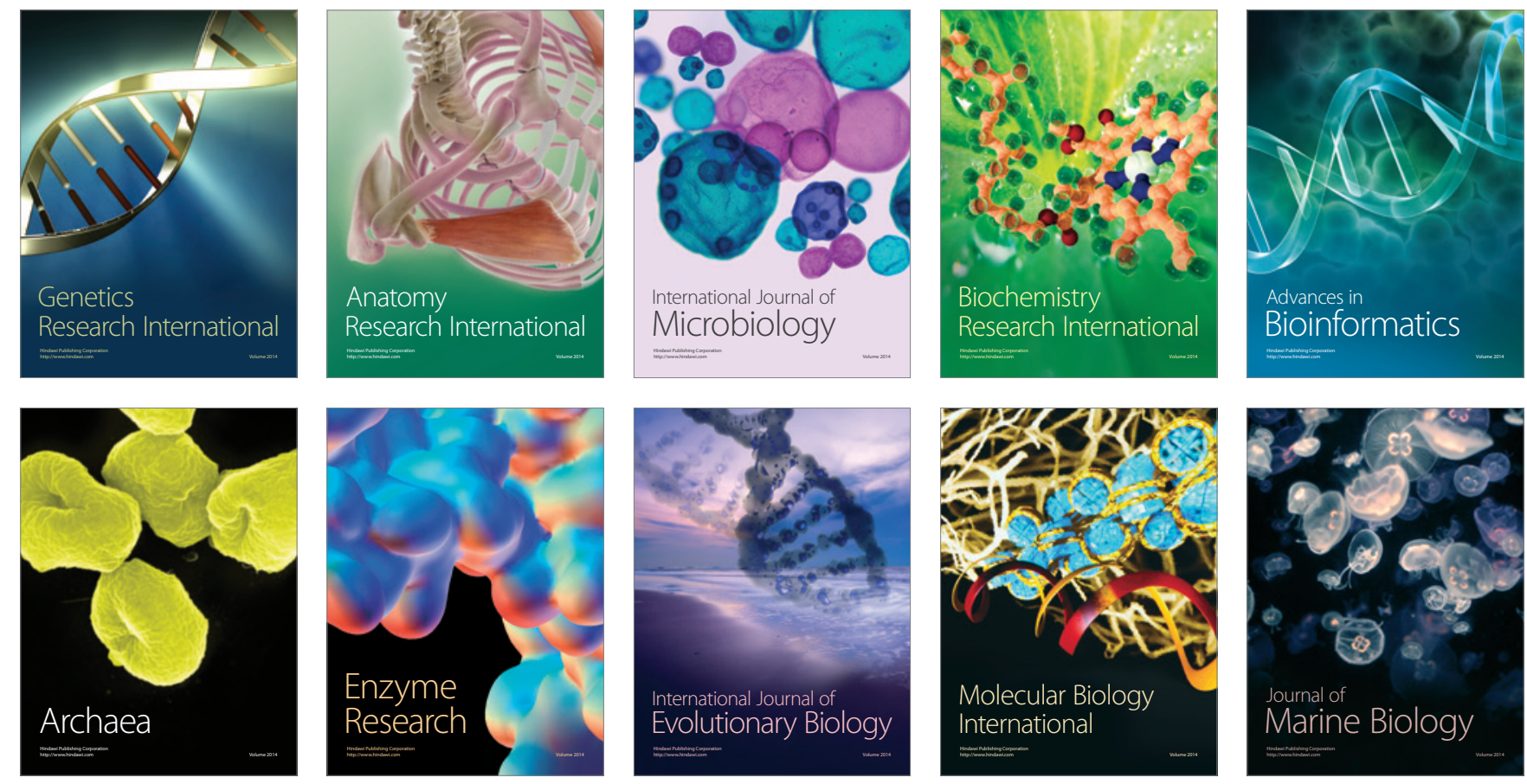